\title{
Concurrent incidence of esophageal squamous cell carcinoma and gastric adenocarcinoma: A case report
}

Yousef Roosta ${ }^{1}$, Farhad Behzadi ${ }^{1}$, Mortaza Raeisi ${ }^{2}$, Mohammadreza Mohammad

Hosseiniazar $^{1}$, and Amin Sedokani ${ }^{1}$

${ }^{1}$ Urmia University of Medical Sciences

${ }^{2}$ Tabriz University of Medical Sciences

February 6, 2021

\begin{abstract}
Although both esophageal and gastric cancers are highly prevalent, the prevalence of both esophageal and gastric cancers simultaneously is very rare overall. Herein, we present a case of simultaneous occurrence of two cancers including esophageal squamous cell carcinoma and gastric adenocarcinoma.
\end{abstract}

\section{Hosted file}

CASE REPORT-CANCER (with figures) (2).pdf available at https://authorea.com/users/394179/ articles/507622-concurrent-incidence-of-esophageal-squamous-cell-carcinoma-and-gastricadenocarcinoma-a-case-report 


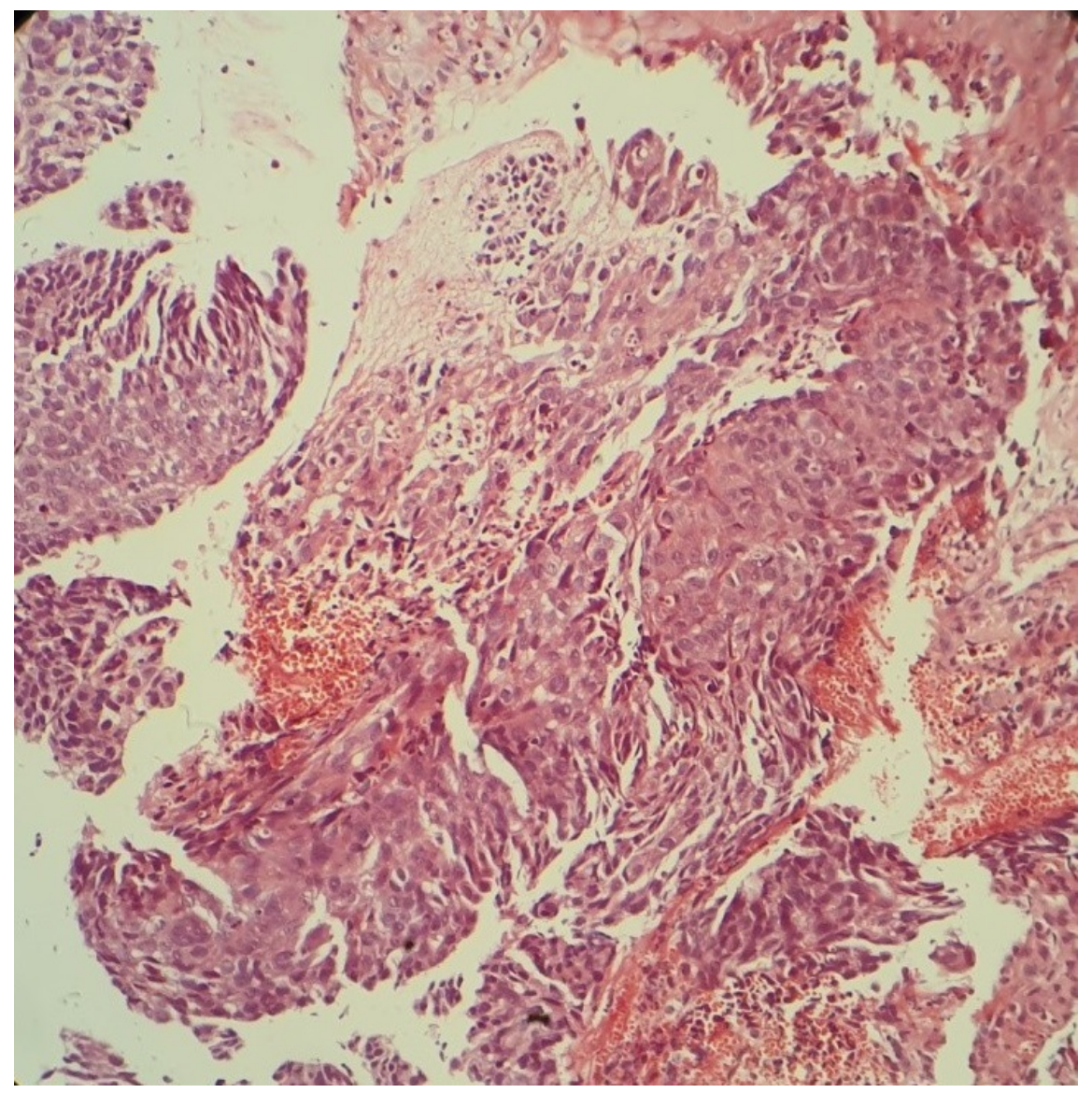




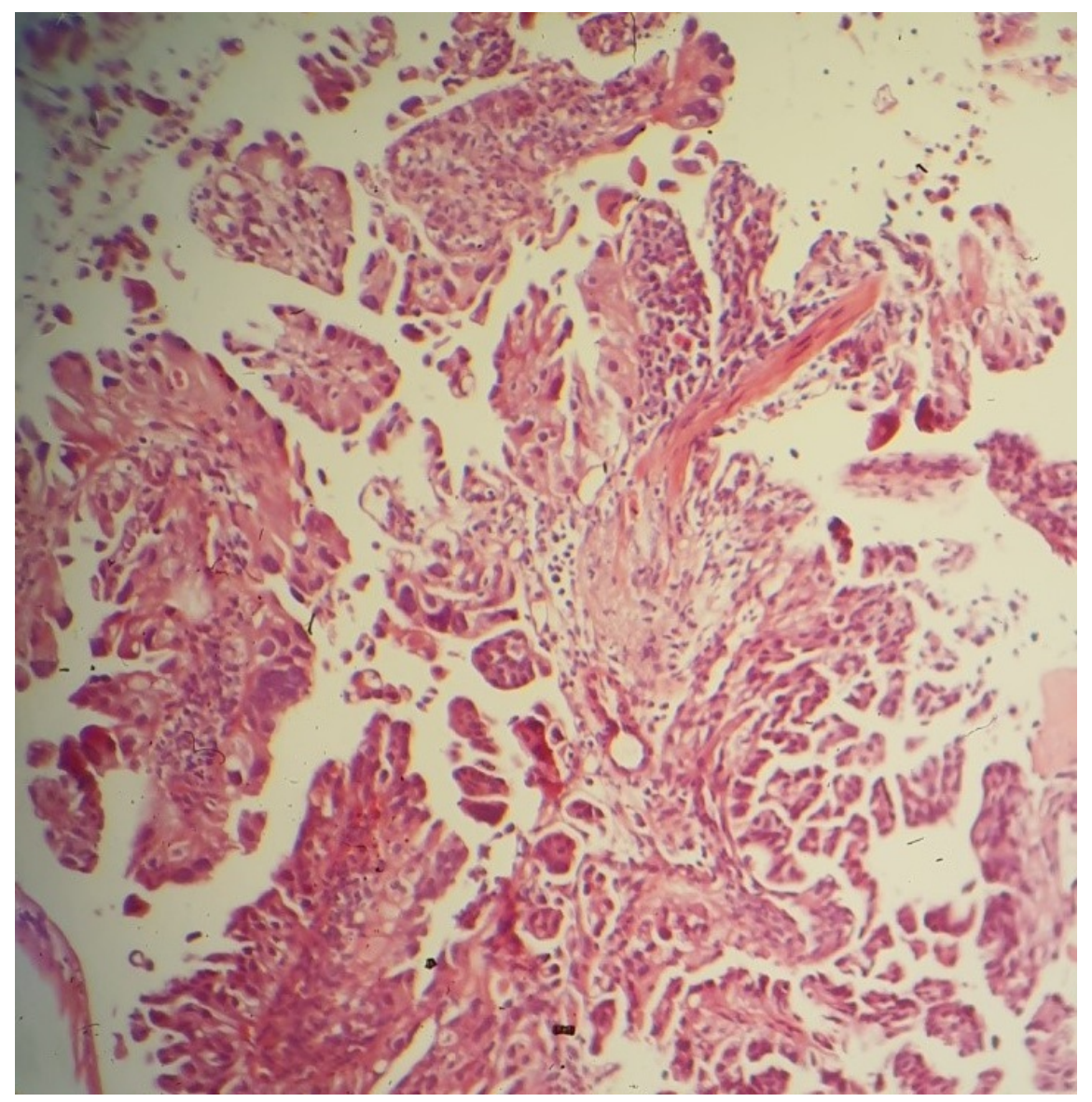




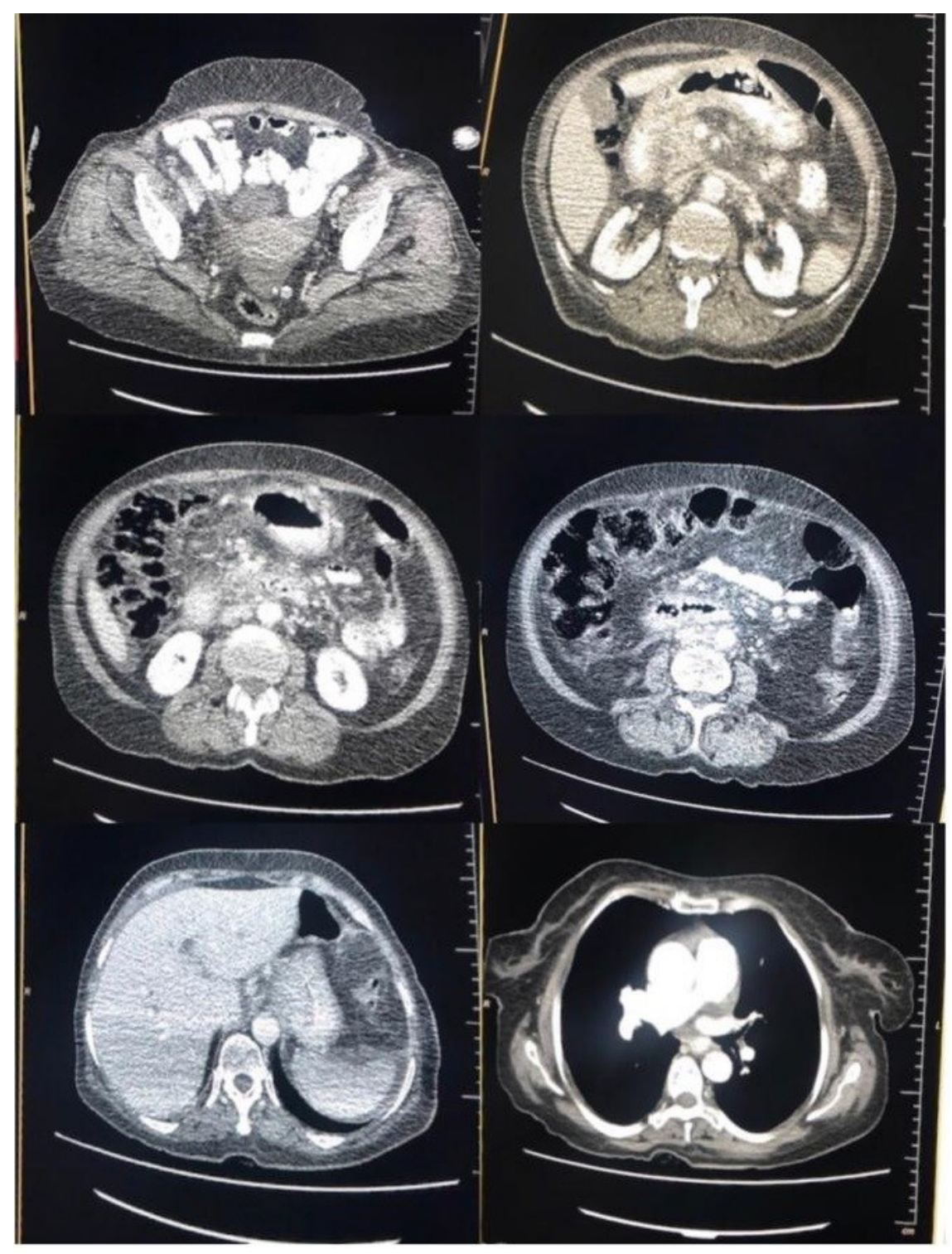

